\title{
Os Encontros e Desencontros da Militância e da Vida Cotidiana ${ }^{1}$
}

\author{
Bernadete Baltazar ${ }^{2}$ \\ Universidade Federal do Espírito Santo
}

\begin{abstract}
RESUMO - O presente trabalho teve como objetivo identificar como as lideranças de organizações populares na Grande Vitória avaliam a relação entre sua militância e a vida cotidiana. Foram entrevistadas doze lideranças - seis mulheres e seis homens. Os dados foram submetidos à análise de conteúdo e revelaram que a militância representa dificuldades, tais como pouco tempo para si mesmo e para a convivência familiar. Entretanto, permite também realização e crescimento pessoal, sendo feita com prazer. Os dados também indicam a existência de contradições entre a prática e o discurso. Dessa forma, os resultados apontam para o desafio atual da militância envolvendo tanto a transformação pessoal como das condições objetivas de vida da população.
\end{abstract}

Palavras-chave: participação popular; processos psicossociais; psicologia social.

\section{Popular Participation and Daily Life: Encounters and Disengagement}

\begin{abstract}
This paper aimed to identify how the leaderships of popular organizations in metropolitan region of Vitória value the connection of their militancy and their daily live. Twelve leaders were interviewed - six women and six men - and the data were submitted to content analysis. The data revealed that militancy presents some difficulties, such as little time to themselves and to their family. However, it represents a way for personal realization and growing, when done with pleasure. The data also point to some contradictions between practice and speech. So, the results indicate a challenge for militancy, which comprehends personal changes as much as changes in the objective conditions of the population's life.
\end{abstract}

Key words: popular participation; psycho-social process; social psychology.

Os movimentos sociais têm sido alvo de estudos das mais diversas áreas do conhecimento, pois demonstram importância social e política à medida que representam a capacidade de organização popular em busca da democracia social, da participação política e de construção da cidadania. Convivem também com o imobilismo das pessoas frente às situações e problemas vigentes e, a despeito desses momentos de apatia e de dificuldade de mobilização, continuam existindo, se estruturando e reestruturando.

Um estudo desses movimentos sob a perspectiva da psicologia social permite compreender os processos psicossociais presentes na militância, pois os mesmos não existem independentes da ação humana. Dessa forma, analisar esses movimentos sociais perpassa a compreensão das mulheres e dos homens que os constituem, daqueles que, apesar das dificuldades que enfrentam, ainda se mantêm na "luta" para organizar e conscientizar a população; que buscam construir uma nova sociedade.

Para a realização desse estudo, utilizamos como suporte teórico os conceitos de identidade, atividade, consciência e emoção, apontadas como categorias fundamentais na construção do psiquismo, pois, "somos as atividades que

1 Artigo derivado da Dissertação de Mestrado desenvolvida sob a orientação da Prof ${ }^{a}$ Maria de Fátima Quintal de Freitas com auxílio financeiro fornecido pela CAPES.

2 Endereço: Rua Sete de Setembro, 270/302 Centro, Vitória, ES, Brasil 29015-000 E-mail: berbal@zaz.com.br desenvolvemos, somos a consciência que reflete o mundo e somos afetividade que ama e odeia este mundo e com esta bagagem nos identificamos e somos identificados por aqueles que nos cercam" (Lane, 1995, p. 62).

Ora, ao pensarmos na liderança de movimento popular, podemos analisá-la considerando as características que Ciampa (1994) aponta nos seus estudos sobre identidade. A identidade de uma liderança de movimento popular, como uma totalidade, é constituída pela diversidade do que esta liderança é, porque cada grupo a que essa liderança pertence fornece um "fragmento" de sua identidade.

Ao sermos nomeados recebemos uma qualificação, uma substantivação que nos determina. Ao interiorizarmos as atribuições que recebemos, "a atividade coisifica-se sob forma de uma 'personagem' que subsiste independentemente da atividade que a engendrou e que deveria sustentar" (Ciampa, 1994, p. 133). Porém, "a manifestação do ser é sempre uma atividade" (Ciampa, 1994, p. 132), pois é através da atividade que o homem, continuamente, vai produzindo sua própria existência. Ao falarmos, por exemplo, que alguém é um militante de movimentos sociais, podemos dizer que o ser militante só acontece quando a atividade fazer militância existe. E mais ainda, que essa identidade se mantém à medida que esse militante exerce sua atividade e comparece diante de um grupo que pressupõe essa identidade e a re-afirma, atualizando-a, mantendo-a, podendo ser cristalizada.

Neste contexto, destacamos a militância como uma atividade que constitui o psiquismo dessas lideranças. 
Compreendemos a militância como uma forma de participação política engajada e crítica, na qual são desenvolvidas ações voltadas para a conscientização política da população, buscando desenvolver novos valores que possibilitem às pessoas se organizarem e lutarem para a construção de uma sociedade justa e digna.

Entretanto, é comum as famílias reclamarem da ausência, em casa, de pais, filhos, maridos e mulheres. Algumas vezes, a militância pode ser sentida, pela família ou amigos, como "alguém" que impede ou rouba esses militantes do convívio diário. Também é comum ouvir as pessoas dizerem que não têm tempo para o lazer, para estudar e que precisam de mais tempo para dedicar a si próprias. E isso pode estar levando o “ indivíduo (...) [a subordinar] sua felicidade pessoal, seus sonhos, suas necessidades e sua vida cotidiana aos objetivos do projeto coletivo." (Nascimento, s.d., p. 15).

Cruz (1988), em seu estudo sobre a identidade de exmilitantes de grupos de esquerda, aponta que o abandono da militância muitas vezes é precedido de sentimentos de apatia, descrença e desgaste - tanto ao nível físico como psicológico - quanto a permanecer atuando. É como se os interesses grupais e pessoais fossem incompatíveis e a importância de cuidar dos interesses e necessidades individuais (família, afeto, trabalho) acabasse por se tornar justificativa para o abandono da militância.

Quando os militantes das organizações populares empenham-se na luta pelos direitos dos cidadãos, objetivam desde a concretização de condições mínimas de infra-estrutura nos bairros (saneamento, transportes) até a garantia de um sistema educacional e de saúde, por exemplo, que permitam ao homem, à coletividade, viver dignamente. Mas, ao buscar a satisfação das necessidades do gênero humano, estão em jogo também a satisfação e a realização das necessidades particulares e individuais, porque "a elevação ao humanogenérico não significa jamais uma abolição da particularida$d e$ " (Heller, 1992, p. 24), e nem tampouco um desligamento completo das atividades cotidianas que, segundo a autora, se compõem da "organização do trabalho e da vida privada, os lazeres e o descanso, a atividade social sistematizada, o intercâmbio e a purificação" (Heller, 1992, p. 18).

O presente artigo é parte de uma dissertação de mestrado e tem como propósito discutir a avaliação que as lideranças de movimentos populares fazem da relação entre a militância e suas vidas cotidianas. Cabe ressaltar que compreendemos a militância política como parte do cotidiano dessas lideranças, mas que para efeito deste trabalho estabelecemos "vida cotidiana" como os aspectos relacionados à vida familiar, ao trabalho, as relações de amizade, dentre outros.

\section{Metodologia}

Entre as décadas de 1960 e 1990, o Brasil passou por profundas alterações e modificações em seu contexto sócio-econômico-político e as lutas e organizações tiveram importante papel nesse processo. Dessa forma, buscamos considerar os diferentes contextos em que as lideranças se inseriram nas lutas e organizações populares, pois, havia uma hipótese inicial de que tal fato poderia ter influência sobre a concepção de militância e a forma de participação assumida pelas lideranças.
Foi então realizado um Estudo Exploratório e foram considerados três (03) períodos de inserção na militância, a saber: $1^{\circ}$ período - após 1964 , com a instauração da ditadura militar até final da década de 1970, quando ocorre o início da abertura política; $2^{\circ}$ período - entre 1980 e 1985 , caracterizado pela transição democrática no país e pela articulação dos diversos movimentos populares; $3^{\circ}$ período - entre 1986 e 1994, sendo caracterizado pelo restabelecimento da democracia no país, aliado ao avanço dos movimentos organizados no que diz respeito à garantia constitucional de mecanismos de participação popular e, ao mesmo tempo, pela dificuldade em mobilizar e organizar a população para suas ações.

Foram estabelecidos como critérios para seleção dos sujeitos a serem entrevistados: a) o inicio da participação em lutas e organizações populares em um dos três períodos propostos; b) o fato de serem apontados e reconhecidos pelos diversos participantes de organizações populares, como lideranças, mesmo que já não assumissem qualquer cargo formal de direção; c) a participação em alguma forma da organização popular por, no mínimo, três anos.

Foram entrevistados 12 sujeitos, seis mulheres e seis homens, sendo quatro para cada período de inserção. Foi realizada uma entrevista aberta, semi-estruturada, em profundidade que permitia ao sujeito narrar sua própria história. Os dados foram submetidos à análise de conteúdo e distribuídos em três blocos temáticos: $1^{\circ}$ - Trajetória da militância; $2^{\circ}$ - Vida cotidiana e militância e $3^{\circ}$ - Avaliação do movimento popular. Para efeito deste artigo, contudo, serão discutidos os dados referentes ao $2^{\circ}$ bloco.

As lideranças entrevistadas foram identificadas da seguinte forma: $\mathrm{F}$ para as lideranças femininas e $\mathrm{M}$ para as lideranças masculinas. Os números 1, 2 indicam as lideranças do $1^{\circ}$ período de inserção; os números 3,4 para o $2^{\circ}$ período de inserção e 5 e 6 para o último período.

\section{Resultados}

\section{Quem são as lideranças?}

No Quadro 1, é possível identificar os sujeitos entrevistados, quanto ao sexo, período de inserção na militância, idade, estado civil, número de filhos, escolaridade e atividade profissional desenvolvida. Cabe ressaltar também, que todas as lideranças são oriundas das Comunidades Eclesiais de Base $\left(\mathrm{CEB}{ }^{3}{ }^{3}\right)$.

\section{Vida cotidiana e militância}

Os dados aqui apresentados referem-se às avaliações que as lideranças fazem a respeito das vantagens, ganhos e benefícios proporcionados pela militância, bem como as perdas, problemas, dificuldades e desvantagens. Abrangem,

3 As CEB's surgiram no final da década de 1960. Detiveram importante papel na organização e condução de diversas lutas populares durante os anos da ditadura militar, pois, em consonância com os princípios de conscientização através da fé, defendidos pela Igreja, permitiam aos moradores das comunidades se reunirem, refletirem e desencadearem ações para a busca de soluções dos diversos problemas vividos pela população. 
Quadro 1. Identificação dos sujeitos entrevistados

\begin{tabular}{|c|c|c|c|c|c|c|}
\hline Sujeito & $\begin{array}{c}\text { Período de } \\
\text { inserção }\end{array}$ & Idade & Estado civil & Filhos & Escolaridade & Ocupação \\
\hline F01 & $1^{\circ}(1974)$ & 63 & Casada & 10 & Analfabeta & Lavadeira \\
\hline F02 & $1^{\circ}(1978)$ & 38 & Casada & 03 & Superior & Pedagoga \\
\hline F03 & $2^{\circ}(1982)$ & 33 & Solteira & 0 & Superior & Pedagoga/Educadora Popular \\
\hline F04 & $2^{\circ}(1982)$ & 34 & Divorciada & 03 & $2^{\circ} \mathrm{Grau}$ & Bancária/Sindicalista Liberada \\
\hline F05 & $3^{\circ}(1986)$ & 29 & Solteira & 0 & $2^{\circ} \mathrm{Grau}$ & Secretaria \\
\hline F06 & $3^{\circ}(1986)$ & 31 & Solteira & 0 & Superior & Pedagoga/Assessora Parlamentar \\
\hline M01 & $1^{\circ}(1973)$ & 49 & Casado & 03 & $2^{\circ} \mathrm{Grau}$ & Contador Autônomo \\
\hline M02 & $1^{\circ}(1979)$ & 43 & Casado & 03 & $1^{\circ} \mathrm{Grau}$ & Servidor Público Comissionado \\
\hline M03 & $2^{\circ}(1980)$ & 37 & Casado & 03 & $2^{\circ} \mathrm{Grau}$ & Vendedor Autônomo \\
\hline M04 & $2^{\circ}(1982)$ & 33 & Casado & 01 & $2^{\circ} \mathrm{Grau}$ & Liberado PT \\
\hline M05 & $3^{\circ}(1986)$ & 29 & Casado & 02 & Superior em curso & Assessor Parlamentar \\
\hline M06 & $3^{\circ}(1989)$ & 30 & Casado & 0 & $2^{\circ} \mathrm{Grau}$ & Publicitário Autônomo \\
\hline
\end{tabular}

também, a forma como essas lideranças avaliam o convívio entre militantes e o modo como percebem as reações de seus familiares e amigos frente à sua militância.

\section{As vantagens e desvantagens proporcionadas pela militância e os projetos de vida}

Dentre as vantagens apontadas, a principal diz respeito ao crescimento pessoal e profissional, à aprendizagem e à aquisição de conhecimentos. Isso significa que a militância permite a aquisição de novos conhecimentos, possibilitando um crescimento pessoal e profissional. Através da militância puderam aprender sobre si mesmos, sobre as relações pessoais, sobre o mundo, sobre a sociedade, permitindo mudanças de comportamento e possibilitando uma realização pessoal.

(...) aprendi a me relacionar com as pessoas, com a vida, com os problemas, com o mundo, a estar no mundo de uma forma diferente (...) Eu sou uma pessoa muito melhor do que eu poderia ter sido se eu tivesse buscado um caminho sozinha (F03). Eu aprendi muito profissionalmente. Eu cresci. Eu hoje, se tenho uma competência bastante boa, profissionalmente, eu dou graças ao movimento popular. (M03)

Por outro lado, para essas mesmas lideranças (exceto M03), em decorrência de seu engajamento, possuem um tempo limitado para o lazer, para uma maior convivência no bairro onde residem, para si mesmos e principalmente para participar da rotina familiar. "Uma coisa interessante é que tem umas fotos de aniversário de sobrinho e eu nunca estava. Não tem nenhuma foto porque representa a sua ausência em alguns momentos" (F03). Para algumas lideranças, essa falta de tempo pode culminar com a não priorização da própria vida (F06; M02), cujo sentido aponta para a vida pessoal colocada em um segundo plano em relação à militância. "Você vive menos porque você não prioriza a questão da vida pessoal, da vida afetiva, da própria família e da sua própria vida econômica, material, a sua estrutura enquanto pessoa, enquanto grupo de família” (M02).

Outro aspecto interessante a ser notado é que essa mesma militância que propicia um crescimento pessoal, ao mesmo tempo em que limita o tempo de seus militantes, também lhes permite tornarem-se referência, serem úteis, reconhecidos e respeitados pelo seu trabalho (F01; F05; M01; M04). Isso significa que com a sua atuação, essas lideranças tornaram-se conhecidas, sentiram-se úteis e respeitadas pelas outras pessoas, possibilitando um reconhecimento de seu trabalho.

Teve eleição pra presidente do partido e aí eu me senti, de um certo ponto até envaidecido, porque (...) as pessoas falavam assim (...) tem que ser uma pessoa que tenha credibilidade, principalmente no movimento popular, (...) tem que ser você (...), conhece essa coisa toda do movimento. E aí isso foi a recompensa (...) Porque você chega lá num processo de disputa, você vê que tem uma base de 500 (...) não foram ali só pra votar, foram porque acreditam ainda naquele projeto que você começou a discutir lá (...) as pessoas te respeitam. (M04)

Mas por outro lado, a despeito desse reconhecimento e respeito, essa mesma militância também significa a existência de discriminação, rótulo e a falta de compreensão das pessoas sobre a militância (F01; F05; M01; M04; M05). Esse aspecto indica que, em muitas circunstâncias, tanto em termos profissionais quanto políticos e nas relações afetivas e de amizade, as outras pessoas não compreendem as razões pelas quais essas lideranças assumem um trabalho de organização popular, confundindo a militância com interesses eleitorais e rotulando negativamente quem é militante.

Para algumas outras lideranças, a perda sentida, em relação à sua militância, foi em relação à interferência nos estudos formais, quer seja por não ter dado continuidade, quer seja por ter gasto um tempo muito maior para sua conclusão. Não existia uma priorização e para algumas lideranças a militância representou ter aberto mão dos estudos (F03; F04; M04; M06).

É interessante salientar neste ponto, que por um lado, parece existir uma grande valorização do conhecimento informal adquirido através da militância. Mas, por outro lado, também é ressaltada a importância da realização da aprendizagem formal, em função, muitas vezes, de uma cobrança social, nem sempre tão clara, de possuir uma formação universitária. 
Tive acesso a muita coisa que talvez alguém que tá fazendo faculdade não teve (...). Eu acho que a perda foi eu não ter feito uma faculdade (F04). Eu consegui aprender muita coisa que eu não aprenderia em outro espaço. (...) o prejuízo que eu tive no meu inserimento no movimento popular foi ter deixado de estudar. (M06)

Outro fato interessante de se notar, é que essa mesma aprendizagem e aquisição de conhecimentos propiciados pela militância, acabam por gerar uma dificuldade nos diversos relacionamentos em função da linguagem e do conhecimento (M02; M03; M06). Neste caso, as lideranças indicam que o nível diferenciado de conhecimento que possuem e o estilo de linguagem que utilizam acabam por causar um distanciamento de outras pessoas não militantes com as quais convivem - família, amigos, conhecidos - e, em alguns casos, demonstrando uma dificuldade pessoal em conversar assuntos que escapam ao contexto da militância. “(...) porque aí quando você começa nessa militância mais aguerrida, mais exacerbada, também o seu papo já é diferente, a conversa não bate legal (...) uma distância de conhecimento muito grande, aí começa haver alguns desencontros..." (M02).

Também pudemos observar que apesar da militância significar um crescimento pessoal e profissional na vida das lideranças, também implica, para alguns sujeitos, em uma interferência na vida profissional (M01; M02; M04; M06). As razões que apontam para isso, refletem o fato de que ao se envolverem na organização popular, em muitos momentos, se dedicaram menos à própria vida profissional.

Outro aspecto interessante a ser destacado refere-se à reação dos familiares em relação à militância dessas lideranças. Para alguns, inicialmente, existia a não aceitação da militância por parte dos familiares (F01; F04; F05; M01; M04; M05), porque não compreendiam o que faziam, pela pouca formação cultural e política da família e ainda em função de uma situação política municipal permeada pela violência.

Hoje eu tô aqui, ele tá em casa, é aqui que ele almoça, aqui que ele toma banho, aqui que ele janta, aqui que ele dá também o sustento da casa, ... mas ele não dorme aqui, ele dorme lá embaixo, ele dorme separado. Isso tudo porque? Porque ele não aceita, nunca aceitou esse trabalho. (F01)

Essa dificuldade inicial na aceitação da militância por parte dos familiares foi comum entre as lideranças masculinas e femininas dos três períodos de inserção. Mas, na opinião de algumas lideranças é necessário reconhecer que os familiares aceitam a militância. E essa aceitação se revelava, pois não existia uma cobrança efetiva por parte dos familiares, ou ainda porque os familiares entendiam ou participavam de alguma forma de organização popular (F02; F03; M06).

Para outras lideranças, com o tempo, os familiares aprenderam a conviver e aceitaram a militância (F05; M01; M02; M03; M04; M06). E essa aceitação deve-se ao fato de que os familiares também passaram a participar das organizações populares e perceberam a importância da mobilização para mudar a situação social e política vivida pela população. Em outros casos, a aceitação é por que "(...) acostumaram, viram que não tinha jeito” (M01). Contudo, ainda que exista essa aceitação, e até mesmo, conforme avaliam as lideranças
F04; F05 e F06, a admiração e orgulho dos pais pelo seu trabalho, também existem por parte dos familiares uma cobrança da presença em casa e de uma vivência familiar maior (F02; F04; F05; F06; M01; M02; M03; M05). Os filhos(as), companheiros(as), pais e irmãos(ãs) cobram, dessas lideranças, a presença em casa, o tempo para o lazer. Os parentes mais distantes também reclamam da pouca convivência.

A existência de cobranças por parte dos familiares, bem como as dificuldades propiciadas pela militância em relação à família, representam uma enorme variedade de sentimentos e reações pessoais dessas lideranças, que vão se alterando, para alguns, com o passar do tempo. A busca e a necessidade em equilibrar a vida pessoal, familiar e a militância são apontadas pela maioria das lideranças (F02; F03; F04; F05; F06; M02; M04; M05; M06). Ao que parece essa busca no equilíbrio entre a militância e a vida familiar talvez seja uma forma de minimizar as cobranças feitas pelos familiares em relação ao pouco tempo que têm para a convivência em casa. Essa busca se dá através da tentativa de acompanhar de perto a educação dos filhos, em ter mais atividades de lazer junto aos filhos, procurando estar presente na vida familiar nos momentos importantes, buscando estabelecer algumas prioridades em sua atuação como forma de ter mais tempo para si e sua família. Além disso, a necessidade em equilibrar a vida familiar com a militância é considerada importante, pois a família é uma fonte de segurança.

Mas, ainda que exista essa busca em equilibrar a vida familiar e a militância, o fato de existirem cobranças, principalmente por parte dos filhos, leva as lideranças masculinas e femininas a encararem essa cobrança de diferentes formas. As lideranças F02 e F04 indicam ter sensação de culpa por não ter mais tempo para os filhos. Dessa forma, existe uma busca em "lidar racionalmente com as cobranças dos filhos" (F02), evitando deixar-se levar pelo aspecto emocional, e também " a tentativa em não se sentir culpada" (F04), em relação à sua ausência e aos problemas apresentados pelo filho.

Aí eu passei a não tentar carregar culpa (...), a ver como coisa normal, como eu trabalho fora e tenho uma militância e ele tem problema na escola, quantas mães que tá do lado do filho que tem o mesmo problema? Quantas mães que tá dentro de casa e não olha o caderno do filho? (...) Aí falei, não vou carregar mais culpa. (F04)

Por outro lado, para as lideranças masculinas, embora também existam cobranças por parte dos filhos, o que ocorre é uma tentativa em ter mais atividades de lazer com os filhos (M03), ou ainda o fato de que, para os sujeitos M04 e M05, uma de suas atividades de lazer é poder "curtir" os filhos.

Mesmo nas relações de amizades, algumas lideranças indicam que os amigos reclamam da sua ausência (F03; M05; M06). Essa cobrança se dá em função de já não participar das mesmas atividades (F03) ou por não estar, às vezes, presente em algumas atividades de lazer (M06) promovidas pelo grupo de amigos.

Essas lideranças também analisam as relações e o convívio entre os militantes e apontam para aspectos interessantes. Algumas lideranças relatam que, até cerca de 15 anos atrás, existia uma maior confraternização e companheirismo (F01; M01; M04) entre a militância. Isso para alguns ainda é um 
fato (F02), percebendo esse companheirismo quando as pessoas se juntam para completar o dinheiro da passagem que falta para muitos militantes se deslocarem. Entretanto, o quadro atual do convívio entre militantes encontra-se bastante diferenciado. Para um grupo de lideranças (F02; F03; F06; M01; M04) a avaliação feita é de que $o$ círculo de amizade tende a se fechar em torno dos militantes, o que ocorre porque acabam não tendo muito tempo para se relacionar com outras pessoas e também pela dificuldade em relacionar-se com pessoas que não tenham a mesma concepção e visão de mundo. Até mesmo as antigas amizades ficam para trás.

Mas por outro lado, as relações na militância se pautam nas diferentes orientações político-ideológicas dos diversos grupos a que pertencem (F03; F06; M01; M04). Essa convivência acaba por ser sustentada pelas diferenças políticas e ideológicas. Isso significa que as pessoas de diferentes grupos não se misturam, pois os diferentes grupos não falam a mesma linguagem, levando a divergências que se estabelecem em função das diferentes posições políticas e ideológicas. Dessa forma, as pessoas que são mais próximas ideologicamente exibem maior grau de proximidade entre si, podendo acarretar a desvalorização das pessoas que pertencem a grupos diferentes. Nas palavras dessas lideranças é possível perceber tal significado. "E às vezes, o que eu percebo é que quando surge alguém no grupo, que não é da mesma militância que você, ela não consegue se sentir bem” (F06). “(...) cada um tem o seu círculo de conversa (...) então, não se mistura" (M01).

A liderança M02 também salienta que as pessoas $e$ grupos não trabalham suas diferenças para construir um projeto unificado, estando cada um mais preocupado com seu próprio grupo ao invés de um projeto de fato coletivo. Além disso, algumas lideranças apontam também a perda dos laços afetivos, o individualismo, a falta de solidariedade, confraternização e companheirismo (F06; M01; M04). Avaliam que as pessoas não socializam os problemas, não se solidarizam para ajudar a resolver os problemas existentes. Mais ainda, não procuram manter um contato mais próximo, pessoal, existindo um maior conhecimento do militante, mas não da pessoa.

Existe também, conforme avaliam as lideranças F02; F05; M02; M04 e M05, uma disputa de poder e espaço, quer seja entre militantes de grupos ideológicos mais próximos, quer seja entre os membros de grupos ideologicamente distantes, com diferentes posições e visões de movimento popular. Talvez o mais grave, como diz a liderança M04, é que "a disputa tá muito grande. Antigamente, a gente fazia disputa com a direita, hoje nós tamos fazendo disputa entre nós" (M04).

Outro fato apontado é que existe um clima de desconfiança, falta de respeito, ética e democracia (M02; M04). As pessoas são capazes de desrespeitar a vivência democrática; faltando transparência e confiabilidade nos relacionamentos. "porque [as pessoas] não se respeitam mais. (...) Então, hoje nós somos capazes de desrespeitar essa vivência democrática" (M02).

É interessante notar também que, para as lideranças F06 e M04, o clima da militância se estende para outros momentos, mesmo nos momentos de lazer, quando se encontram nos barzinhos. Acaba ficando difícil se desligar da militância, mesmo em outras circunstâncias, até em função do fato de que os militantes, nesses outros momentos, também estão juntos. Por isso, a liderança M04 "prefere programar suas saídas com amigos não militantes, até mesmo porque se você acaba saindo sempre com as mesmas pessoas, você acaba mantendo o clima da militância, sempre a mesma coisa" (M04). Outras lideranças (F01; F02; F04; F05; M02; M04; M05) afirmam que mantêm relações de amizades com militantes e não militantes, buscando cultivar outras amizades, com as quais partilham diferentes momentos de diversão.

Na visão das lideranças F01 e M06, existe uma convivência parecida com uma família, mas uma família diferente, uma convivência na qual as particularidades pessoais não são colocadas. Para a liderança F05, embora os militantes se vejam com freqüência, isso não garante um efetivo conhecimento, pois existe pouco conhecimento sobre o aspecto pessoal do militante.

Em relação ao convívio entre militantes, as lideranças apontam para uma convivência, no geral. Tal dificuldade no convívio tem, ao que parece, como pano de fundo, as diferentes orientações político-ideológicas dos diferentes grupos, que acabam por interferir nas relações interpessoais, à medida que as pessoas desses diferentes grupos não se integram com outros grupos. Além disso, indicam que nessa convivência houve perda dos laços afetivos, revelando grande individualismo, falta de solidariedade, confraternização e companheirismo entre os militantes, acrescidos da disputa de espaço e poder entre os grupos, gerando um clima de desconfiança, falta de respeito, ética e democracia.

\section{Discussão}

\section{Lideranças, militância e vida cotidiana: relações possíveis}

As lideranças deste grupo são oriundas das CEB's, de uma experiência de igreja que lhes propiciou uma leitura da realidade através da ligação fé e vida. Ao que parece, essas lideranças fizeram uma opção em suas vidas, a opção por um projeto coletivo que visa à construção de uma "nova sociedade". Ao assumirem a militância, sentem-se responsáveis por esse projeto coletivo, têm certeza do caminho e da opção feitos, consideram-se uma referência para o trabalho de organização popular, tendo ainda o que fazer, como contribuir. Também se sentem como aprendizes (porque a atuação é também um espaço de aprendizagem) desse mesmo trabalho.

Podemos constatar que as expectativas apontadas por essas lideranças revelam que esses sujeitos, compreendidos como homens genéricos e particulares, tal como Heller (1992) discute, têm colocado suas paixões, desejos e particularidades na construção de um projeto que abarca realizações que vão além das realizações e necessidades pessoais. Vivenciam sua "parte" humano-genérica, buscando construir uma sociedade mais justa, contribuindo com o processo de conscientização e organização popular como forma de propiciar mudanças nas condições de vida das pessoas, da coletividade, realizando-se também como homens particulares.

Essa realização, satisfação pessoal pode ser observada quando essas lideranças afirmam que a militância representou 
um marco, um “divisor de águas” em suas vidas, pois puderam vivenciar uma experiência que lhes permitiu mudar, crescer, tanto pessoal quanto profissionalmente. Realizam-se na medida que se tornam respeitadas e reconhecidas pelo seu trabalho (deixam de ser "um" entre muitos e se tornam "um" com uma identidade reconhecida e respeitada). Com a militância, ganham respeito, conhecimentos gerais (adquiridos informalmente), ampliam seus relacionamentos interpessoais (ao mesmo tempo em que os limitam), crescem pessoal e profissionalmente, realizam-se como seres políticos e sociais e ainda crescem na sua própria militância à medida que podem ir avançando e assumindo outras esferas de atuação.

Ao assumirem o compromisso pela construção de um projeto coletivo, apontam para o desenvolvimento da "consciência" sobre uma realidade de exclusão social da grande massa da população brasileira e sobre a necessidade da participação social como forma de mudança dessa realidade.

Mas, conhecer essa realidade por si só não assegura a realização de uma ação transformadora. São necessárias também motivações e desejos pessoais que potencializem e que mantenham essa ação. Como pudemos perceber, ao fazerem essa opção pelo coletivo, essas lideranças desenvolvem a consciência sobre a necessidade da organização e da participação popular e, também se realizam de diferentes formas como indivíduos, pois têm prazer, paixão e gosto pela militância. Esse prazer e essa paixão pela militância contribuem para a continuidade do engajamento na atividade. E como salienta Sawaia (1995):

O aprendizado de uma regra não conduz necessariamente à ação, pois o compromisso político não é uma questão puramente cognitivo-instrumental. Ele é vivido como necessidade do eu, como desejo. Mesmo quando o indivíduo age em nome do bem comum, a ação implica em exercício da motivação individual, portanto a vontade e a afetividade são suas dimensões fundamentais. (...) Bem-estar coletivo e prazer individual não são dicotômicos e o consenso democrático não é conquistado necessariamente à custa do sacrifício pessoal. (pp. 154-155)

Mas, essa mesma militância feita com paixão e prazer, também gera desgastes, cansaço e desafios, tanto em termos de sua própria atuação quanto em sua vida pessoal e familiar. A militância não representa apenas ganhos e realizações, ainda que para alguns, ao se pesar na balança, as perdas sejam proporcionalmente menores do que os ganhos. A militância também tem seus "altos e baixos".

$\mathrm{Na}$ busca da realização do ser genérico, o ser particular arca com alguns ônus. Isso não significa dizer que com essa militância estamos querendo reforçar uma idéia, muito recorrente entre muitos militantes e até ex-militantes, de que o envolvimento e a participação em diversas formas de organização popular gera sofrimento e dor, ou ainda a idéia de que "anos de minha vida se passaram, e o que foi que eu construí?" Pergunta, aliás, que possível ser ouvida, em muitas ocasiões, quando se conversa com militantes. Mas, ao que parece, essa indagação é feita nos momentos em que o desgaste pessoal, a falta de resultados da organização popular, a dificuldade em mobilizar as pessoas para participarem, tomam uma proporção demasiadamente expressiva.
Nesse ponto, cabe destacar a importância em se discutir as relações grupais e o poder. De um lado, existe uma tendência a manter uma relação de maior proximidade com aquelas pessoas que "teoricamente" partilham a concepção de uma sociedade diferente, que pode ser construída numa conjugação de esforços dos diversos grupos populares organizados e, por outro lado, esses mesmos grupos parecem disputar espaço e poder entre si, causando dificuldade nas relações interpessoais e intergrupais.

Destacamos então, Tajfel (1981) que, ao discutir sobre os atributos do comportamento intergrupo, afirma que a existência de um encontro puramente interpessoal é irreal, pois os indivíduos ao se dirigirem a outros indivíduos, fazem-no baseados em uma perspectiva intergrupal, pois “(...) freqüentemente comportam-se antes de mais nada como membros de categorias sociais bem definidas e claramente distintas" (Tajfel, 1981, p. 260). Dessa forma, fica clara a distinção entre o "meu grupo" e o "outro grupo". O autor ainda salienta que quanto mais próximo da perspectiva intergrupal estiver o indivíduo, maior será a uniformidade do comportamento, tornando mais distinto o "meu grupo" do "outro grupo", mantendo relacionamentos interpessoais mais claramente pautados pela ideologia do grupo a que pertence.

Obviamente isso ocorre em todas as situações sociais, mas a grande preocupação que parece decorrer dessa situação específica diz respeito à contradição que emerge. À medida que as relações se pautam em função dos diferentes grupos a que cada um pertence, gastando-se esforços na disputa de espaço e de poder entre esses grupos, a construção do projeto coletivo democrático pode estar se perdendo. Por que se perdendo? Construir a democracia pressupõe a convivência com a divergência, com a diferença na construção de um projeto coletivo. A partir do momento em que se torna praticamente impossível conviver com a divergência, existe então a luta pela hegemonia de poder. Partem para o campo de batalha para disputar qual grupo tem maior poder de negociação, qual grupo tem melhores condições de levar adiante a construção do projeto coletivo. O "meu" grupo acaba por se tornar o melhor em relação ao(s) "outro(s)" grupo(s).

Em função desse sentimento de pertença e de identificação com determinados grupos, essas lideranças podem estar incorporando em suas vidas, essa linguagem, esse conhecimento, essa ideologia defendida e proposta por seus grupos. Isso pode estar propiciando, então, dificuldades nos relacionamentos interpessoais, com militantes de diferentes grupos - ainda que teoricamente próximos ideologicamente - com grupos mais distantes ideologicamente e com outras pessoas que não tenham qualquer tipo de militância.

Podemos pensar, então, que os diferentes grupos, ao se empenharem na briga pelo espaço e pelo poder, fazem-no por considerarem o "meu" grupo como o único possível de levar adiante o processo de construção de uma nova sociedade. Esse poder simbólico pode ser originado através do alto grau de identificação, senso de pertinência e valoração positiva que seus membros atribuem a seu grupo, baseados na carga afetiva que o mesmo representa na vida de cada um de seus membros. Tal fato pode gerar uma imagem altamente positiva desse grupo e, ao disputarem espaço e poder - como forma de manter essa imagem positiva do grupo - buscam conseqüentemente manter uma auto-imagem positiva de si 
mesmos. Mas podem, com isso, estar tornando os limites entre um grupo e outro grupo cada vez mais distintos e rígidos. "A proposta do 'meu' grupo é sempre melhor do que a proposta do outro grupo".

Talvez seja importante considerar, tal como Sawaia (1995), que "a ação participativa pode e deve ser local, específica e motivada por interesses pessoais e grupais, mas o horizonte deve ser universal para não se tornar corporativista" (p. 157).

Podemos também refletir tais aspectos até aqui vistos a partir da perspectiva de que a realização do homem genérico (construção de uma nova sociedade) perpassa pela realização do homem particular, pela construção das subjetividades, das particularidades, dos afetos e desejos daqueles que optam pelo coletivo.

Até o início da década de 70, o movimento socialista no mundo cultivava a imagem do militante quase como a de um superhomem. Abnegado, totalmente dedicado à causa, disciplinado, este ser secundarizava completamente sua vida pessoal (quando não abria mão totalmente dela) em função de um ideal mais amplo: a vitória da revolução, que abriria caminho para a emancipação da humanidade. (José, 1996, p. 27)

Atualmente, existe uma preocupação com o fato de que esses militantes, que fazem uma opção pela construção de um projeto coletivo, que em muitos momentos, como vimos nos resultados apresentados, ainda deixam em segundo plano suas necessidades pessoais em função de militância. Mais ainda, são produtos e produtores da realidade social e também devem ser considerados em sua dimensão individual e particular. Ao mesmo tempo que produzem a militância, os militantes também são produzidos por ela. As discussões mais recentes em torno da militância apontam para a necessidade de pensar esse "militante" não mais como um "super-homem”, e que "a opção pela política (...) não pode mais significar um esmagamento da individualidade (...) $O$ indivíduo pode realizar-se no território público, contribuindo para transformá-lo" (José, 1996, p. 31).

Buscar a construção de novas condições objetivas de vida, nas quais o homem possa viver melhor com o mínimo de dignidade, também implica em construir novas subjetividades, que darão suporte e continuarão a reproduzir essas novas condições de vida. Talvez, por isso, esses militantes oscilem entre a produção de identidades emancipadas e conservadoras. Emancipadas no que diz respeito à opção de vida pela coletividade, na busca do bem-estar coletivo, na percepção de que suas vidas pessoais se completam, se realizam no meio social. Conservadoras quando reproduzem papéis cristalizados que pouco contribuem para produção de novos papéis sociais, por exemplo, de pai/mãe, de homens e mulheres ${ }^{4}$. Além disso, ainda que de modo menos caricatural

4 Embora os dados da pesquisa apenas façam algumas sugestões em relação a esse aspecto, isso pode ser claramente observado em conversas informais entre militantes. A reclamação de que os "maridos militantes", "pais militantes" adotam posturas completamente destoantes de seu discurso de militância é muito comum. Falam da democracia, discursam sobre a dominação, mas ao mesmo tempo não partilham as tarefas domésticas, a educação dos filhos. do que o militante "tarefeiro" e "abnegado", também oscilam na emancipação/conservação de uma outra identidade, a de militante, já que se mostram "ativistas", tendo pouco tempo para si mesmos, mas também apontam para a necessidade de exercer uma militância em que possam equilibrar vida pessoal e familiar.

Ao que nos parece, a atividade e a identidade do militante ainda se encontram cristalizadas. Mas isso não significa dizer que não possam ser mudadas. Afinal, concebemos a identidade como movimento, como transformação, portanto passível de se metamorfosear em uma nova identidade.

Talvez por isso mudá-la, transformá-la seja um desafio cotidiano. Um desafio que implica em mudanças objetivas e subjetivas, como por exemplo, externalizar no cotidiano, nas relações mais próximas, aquilo que se lê, aquilo que se reflete em conjunto, aquilo que se discursa em relação à abolição da dominação e da exploração, não mais como um discurso teórico, mas sim como uma prática. Expressar nessa prática não só o aspecto racional da necessidade de superação das mais diversas formas de exploração e injustiça, mas expressar também o componente afetivo e emocional, sentindo a necessidade de mudanças e interiorizando essa prática, tornando-a subjetiva. Dessa forma, essa subjetividade pode ser objetivada, tornando a ação cotidiana consistente e concreta.

Metamorfosear-se em um "novo militante", significa articular, no cotidiano concreto das relações, duas dimensões essenciais: o homem, suas particularidades e desejos e o seu contexto social-histórico-político-econômico. Dessa forma, o contexto da atualidade em nosso país aponta para a necessidade de uma prática de esquerda, que como diz Sader (1995), significa

(...) participar da reinvenção concreta de uma nova sociedade, baseada na justiça social e na solidariedade, na realização prática dos direitos da cidadania sem qualquer tipo de exclusão. Significa lutar e concretizar um mundo de educação, de cultura, de autonomia individual e realização social. (p. 95)

Ou ainda, como Heller (1992) esclarece

Marx disse que, transformando o mundo, os homens se transformam a si mesmos. Não modificaremos, substancialmente o seu pensamento se alterarmos a sua frase e afirmamos agora que não podemos transformar o mundo se, ao mesmo tempo, não nos transformamos a nós mesmos. (p. 117)

\section{Considerações Finais}

Ao que parece, de fato, estamos frente a um grande desafio. Construir o bem-estar coletivo, fortalecer a noção da coletividade, contudo sem desconsiderar o indivíduo particular. Transformar a nós mesmos, ao mesmo tempo em que buscamos transformar o "mundo".

O que pudemos observar com o trabalho, é que a militância e a vida cotidiana, em muitos momentos, representam desencontros e encontros. A militância, ao mesmo tempo em que propicia algumas dificuldades e perdas na vida de suas lideranças - embora não represente dor e sofrimento, abdicação completa da vida pessoal - propicia também 
prazer, paixão, crescimento, mudanças pessoais nas relações consigo mesmo e com o mundo, confere poder e status. Existem contradições entre a prática discursiva e a prática não discursiva nos diversos grupos de movimentos organizados e, mais ainda, existe também a preocupação dos próprios militantes em relação a essas contradições. A percepção dessas contradições talvez seja um dos caminhos para que outras mudanças e crescimento possam ocorrer, possibilitando novas práticas que permeiem a construção da nova sociedade e do novo homem.

Portanto, acreditamos que cabe à Psicologia, uma psicologia crítica e comprometida, buscar compreender o homem na sua inter-relação com os fenômenos sociais, possibilitando ao próprio homem se perceber como sujeito de sua história, como portador de particularidades, desejos, afetos, emoções que se constituem socialmente. Homem passível de mudar a si mesmo, mudar as suas relações sociais e o seu próprio contexto social, resgatando a dignidade em viver; superando, como afirma Sawaia (1995), o "tempo de morrer" - tempo em que as emoções estão aprisionadas, o tempo em que o sentimento de impotência e de que nada existe por se fazer torna inerte a própria ação na busca da realização como ser particular e genérico. Nesse sentido, parece fundamental promover estudos que procurem compreender os aspectos psicossociais presentes na militância, pois poderão gerar subsídios para mudanças no âmbito das relações interpessoais e intergrupais, propiciando a construção de identidades emancipadas em uma sociedade emancipada.

\section{Referências}

Ciampa, A. C. (1994). A estória do Severino e a história da Severina - Um ensaio de psicologia social ( $4^{\mathrm{a}}$ ed.). São Paulo: Brasiliense.

Cruz, R. C. A. (1988). A identidade de ex-militantes de grupos de esquerda. Tese de Doutorado, Pontifícia Universidade Católica, São Paulo.

Heller, A. (1992). O cotidiano e a história (4ª ed.). Rio de Janeiro: Paz e Terra.

José, E. (1996). Em busca da militância perdida, Revista Teoria e Debate, 9(32), 28-32.

Lane, S. T. M. (1995). A mediação emocional na constituição do psiquismo humano. Em S. T. M. Lane \& B. B. Sawaia (Orgs.), Novas veredas da psicologia social (pp. 55-63). São Paulo: Brasiliense/EDUC.

Nascimento, C. (s.d.) Marxismo, Cotidiano e Subjetividade. Cadernos Fé \& Política, 5, 10-20.

Sader, E. (1995). O anjo torto - esquerda (e direita) no Brasil. São Paulo: Brasiliense.

Sawaia, B. B. (1995). Dimensão ético-afetiva do adoecer da classe trabalhadora. Em S. T. M. Lane \& B. B. Sawaia (Orgs.), Novas veredas da psicologia social (pp. 157-168). São Paulo: Brasiliense/EDUC.

Tajfel, H. (1981). Grupos humanos e categorias sociais. Lisboa: Livro Horizonte.

\section{OFERTA ESPECIAL}

Psicologia: Teoria e Pesquisa oferece um desconto especial de $20 \%$ na assinatura individual para estudantes de graduação ou pós-graduação para pedidos de, no mínimo, 10 assinaturas. A solicitação deste desconto especial deverá ser acompanhada de comprovante da respectiva instituição de ensino, ou carta assinada por professor, que ateste a condição de aluno dos solicitantes. 